\title{
Happy eating: the single target implicit association test predicts overeating after positive emotions
}

Citation for published version (APA):

Bongers, P., Jansen, A., Houben, K., \& Roefs, A. (2013). Happy eating: the single target implicit association test predicts overeating after positive emotions. Eating Behaviors, 14(3), 348-355. https://doi.org/10.1016/j.eatbeh.2013.06.007

Document status and date:

Published: 01/01/2013

DOI:

10.1016/j.eatbeh.2013.06.007

Document Version:

Publisher's PDF, also known as Version of record

Document license:

Taverne

Please check the document version of this publication:

- A submitted manuscript is the version of the article upon submission and before peer-review. There can be important differences between the submitted version and the official published version of record.

People interested in the research are advised to contact the author for the final version of the publication, or visit the DOI to the publisher's website.

- The final author version and the galley proof are versions of the publication after peer review.

- The final published version features the final layout of the paper including the volume, issue and page numbers.

Link to publication

\footnotetext{
General rights rights.

- You may freely distribute the URL identifying the publication in the public portal. please follow below link for the End User Agreement:

www.umlib.nl/taverne-license

Take down policy

If you believe that this document breaches copyright please contact us at:

repository@maastrichtuniversity.nl

providing details and we will investigate your claim.
}

Copyright and moral rights for the publications made accessible in the public portal are retained by the authors and/or other copyright owners and it is a condition of accessing publications that users recognise and abide by the legal requirements associated with these

- Users may download and print one copy of any publication from the public portal for the purpose of private study or research.

- You may not further distribute the material or use it for any profit-making activity or commercial gain

If the publication is distributed under the terms of Article $25 \mathrm{fa}$ of the Dutch Copyright Act, indicated by the "Taverne" license above, 


\title{
Happy eating: The Single Target Implicit Association Test predicts overeating after positive emotions
}

\author{
Peggy Bongers*, Anita Jansen, Katrijn Houben, Anne Roefs \\ Faculty of Psychology and Neuroscience, Maastricht University, CPS, Department of Eating Disorders E Addiction, P.O. Box 616, 6200 MD Maastricht, The Netherlands
}

\section{A R T I C L E I N F O}

Article history:

Received 3 December 2012

Received in revised form 22 March 2013

Accepted 7 June 2013

Available online 28 June 2013

\section{Keywords}

Emotional eating

Implicit Association Test

Dutch Eating Behavior Questionnaire

Food intake

Mood

\begin{abstract}
A B S T R A C T
For many years, questionnaires have been considered the standard when examining emotional eating behavior. However, recently, some controversy has arisen about these questionnaires, and their usefulness in identifying emotional eaters has been questioned. The current study aimed to investigate the Single Target Implicit Association Test (ST-IAT) as a measure of emotional eating. Two ST-IATs (assessing food-positive and food-negative associations respectively) and the Dutch Eating Behaviour Questionnaire (DEBQ) were compared in undergraduate students. A positive, negative or neutral mood was induced by means of a film clip, and milkshake consumption was measured during and after the mood induction. It was hypothesized that participants with strong emotion-food associations on the ST-IATs (i.e., IAT-emotional eaters) would consume more food in the emotion induction condition corresponding to that emotion, as compared to those with weak emotion-food associations as well as to those in the neutral condition. Participants who scored high on both the positive and negative ST-IATs ate more during a positive mood induction than during a negative mood induction. This effect did not extend to milkshake consumption after the mood induction procedure. In addition, IAT-positive emotional eaters consumed more food than IAT-non-emotional eaters. No effects of the DEBQ on milkshake consumption were found. It is concluded that the ST-IAT has potential as a measure of emotional eating.
\end{abstract}

(c) 2013 Elsevier Ltd. All rights reserved.

\section{Introduction}

Most people have at one time or another experienced how emotional states influence their eating behavior. They may have not been able to eat when grieving or in love, or celebrated happy events or achievements with big dinners. However, for some people, eating and emotions have become too interconnected. So much, in fact, that they have considerable difficulties distinguishing emotional arousal from feelings of hunger or food desires, and even confuse emotions for hunger or desire. This observation was first made by Bruch (1964), and in the years thereafter interest in the concept of 'emotional eating' has grown (Van Strien, Frijters, Bergers, and Defares, 1986).

To measure emotional eating, several questionnaires have been developed (Emotional Eating Scale (EES) (Arnow, Kenardy, and Agras, 1995); Emotional Overeating Questionnaire (EOS) (Masheb and Grilo, 2006); Emotional Eating subscale of the Dutch Eating Behavior Questionnaire (DEBQ) (Van Strien et al., 1986)). Although the design of these questionnaires may vary, they all have the same goal: to retrospectively self-assess eating behavior in response to (mainly) negative emotions. A significant problem that arises with this kind of measure is that people are generally not very good at recalling their emotions, not good at

\footnotetext{
* Corresponding author. Tel.: + 3143388 1582; fax: + 31433884196. E-mail address: peggy.bongers@maastrichtuniversity.nl (P. Bongers).
}

recalling their eating behavior, and not good at all at recalling associations between the two. Evers, de Ridder, and Adriaanse (2009) therefore suggest that emotional eating scales may suffer from a triple recall bias'. Along the same lines, the idea that emotions and eating are related is a kind of common sense in the general population, which may lead people to be biased towards experiences that confirm this notion (Ganley, 1989). These problems with current emotional eating scales might explain recent findings that show that scores on such scales are poor predictors of food intake following induction of a positive or negative mood. Evers et al. (2009) conducted five studies in which positive and/or negative emotions were induced in emotional and non-emotional eaters as identified by the DEBQ subscale of emotional eating, before subjecting them to a bogus taste test. The way of inducing mood states (e.g., film excerpts or false feedback) and the type of mood induced (e.g., sad, happy or anxious) varied over studies. None of the studies showed increased food intake in DEBQ-emotional eaters as compared to non-emotional eaters, in either emotional or neutral conditions. Conner, Fitter, and Fletcher (1999) conducted a study in a more naturalistic setting in which participants kept track of daily hassles (i.e., stress) and filled out food diaries for one week. They found that, although the amount of daily hassles was positively related to snacking, this relationship was moderated by external eating (i.e. eating after being exposed to food stimuli), but not DEBQ-emotional eating. Another naturalistic study (Adriaanse, de Ridder, and Evers, 2011) was also unable to discover an influence of DEBQ-emotional eating 
scores on snacking, neither under neutral nor emotional circumstances. Adriaanse et al. (2011) subsequently hypothesized that emotional eating scales measure a person's beliefs about the association between emotions and eating, but not their actual eating behavior in response to negative emotions. These personal beliefs would follow from concern about one's own eating behavior. Indeed, Adriaanse et al. (2011) showed that higher self-reported emotional eating scores are significant correlates of more worrying about and monitoring of one's own eating behavior, lower control over one's eating behavior, and a higher extrinsic motivation for healthy eating. A similar suggestion was made by Jansen et al. (2011), who found that there was no discriminant validity of the emotional and external eating scales of the DEBQ and a moderate correlation between the subscales. Jansen et al. (2011) concluded that the DEBQ and possibly other eating scales as well, do not distinguish between emotional, external and restraint eaters, but simply indicate a general 'eating concern' in high-scoring people. A final problem with the emotional eating scales is that they mostly focus on negative emotions, while neglecting positive emotions, even though research has shown that positive mood can also increase food intake compared to neutral mood (Cools, Schotte, and McNally, 1992; Patel and Schlundt, 2001; Turner, Luszczynska, Warner, and Schwarzer, 2010).

To overcome the problems related to self-report eating scales, the present study tested whether a Single Target Implicit Association Test (ST-IAT; Karpinski and Steinman, 2006) is a better measure of emotional eating. The Implicit Association Test (IAT; Greenwald, McGhee, and Schwartz, 1998) is an implicit measure of associations between concepts. Implicit measures are defined by De Houwer, Teige-Mocigemba, Spruyt, and Moors (2009) as "measurement outcomes that are causally produced by the to-be-measured attribute in the absence of certain goals, awareness, substantial cognitive resources, or substantial time" (p. 350). In the IAT, participants distinguish two categories of words (e.g., pleasant and unpleasant; the attributes) presented on the screen, as well as two other categories of words or pictures (e.g., flowers and insects; the target-concepts), by either a left-hand or right-hand response. The general idea is that when associated attributes and targetconcepts require pressing the same response button (e.g., right-hand response for flowers and pleasant words), responses are faster than when unassociated attributes and target-concepts share the same response key (e.g., right-hand response for insects and pleasant words). This difference in response time is taken as an implicit measure of an association between the target and attribute categories. The ST-IAT is a modification of the original IAT in that there is only one target category, and it has been found to be equally reliable as the IAT (Karpinski and Steinman, 2006). For the current study, the target-concept is food, and the attribute categories are 'emotional' and 'neutral'. To measure associations between food and both positive and negative emotions, two ST-IATs are administered.

The hypothesis is that high emotional eaters can be distinguished from low emotional eaters based on their ST-IAT performance: Participants with stronger ST-IAT food-emotion associations (referred to as 'IAT-emotional eaters') will (1) consume more food after an emotion induction than after a control procedure, and (2) show higher food intake in the emotional conditions than participants with weaker ST-IAT foodemotion associations (referred to as 'IAT-non-emotional eaters'). Furthermore, this overeating is expected to be emotion-specific: those scoring high on IAT-positive emotional eating will overeat in the positive mood condition, while IAT-negative emotional eaters will overeat in the negative mood condition. No effect of emotion induction on food intake is expected for the IAT-non-emotional eaters.

\section{Methods}

\subsection{Participants}

Participants were 122 female undergraduate students at Maastricht University. They were recruited through advertisements at the university, announcing a study on the relationship between empathy and perception. Participants were instructed not to consume any food in the $2 \mathrm{~h}$ prior to the experiment. No exclusion criteria were applied. Participants took part for either course credit or a monetary reward of $€ 7.50$. The study's procedure was approved by the local ethical committee.

\subsection{Measures}

\subsubsection{ST-IAT}

Stimuli of the ST-IAT included neutral words (6), emotion words (6) and food words (6). Attribute category labels were presented in the top left ('neutral') and top right ('emotion') corners of the screen, and these remained on screen during the task. The target category label (i.e., 'food') was situated either below the 'neutral' label or below the 'emotion' label. Stimulus words and pictures were presented in the middle of the screen. Participants were instructed to sort the presented stimulus words by a button press (left or right) according to the category labels on screen. Stimuli remained on the screen until a response was given. After a practice-block of 24 trials with only neutral and emotional words, the combined ST-IAT blocks were presented, each consisting of 84 trials. Of these trials, 60 were attribute (i.e., emotional and neutral words) trials and 24 were target (i.e., food pictures) trials. In one block, target food words were combined with emotional words, whereas food words were combined with neutral words in the other block. Order of these blocks was counterbalanced over participants, and participants could take a short break between blocks. A red cross appeared shortly $(500 \mathrm{~ms})$ on the screen when a mistake was made. Within the food-emotion block, participants made 48 responses on the right response key, and 36 responses on the left response key. In the neutralemotion block this was reversed, with 36 right-key and 48 left-key responses being made. Each participant completed two ST-IATs: one with neutral words, positive emotions and high-caloric food pictures, and one with neutral words, negative emotions and high-caloric food pictures. The order of the two ST-IATs was counterbalanced over participants, and participants started with the same block in both ST-IATs (i.e., if a participant started with the food-emotional block in the positive IAT, she also started with the food-emotional block in the negative IAT). Because research has shown that emotional overeating mostly involves palatable, high-caloric food (Ganley, 1989), only these types of food items were used in the task. Table 1 gives an overview of the neutral, positive emotional and negative emotional words that were used, as well as the content of the food pictures.

\subsubsection{Films}

Participants watched either a positive, negative or neutral film fragment, lasting for approximately $2 \mathrm{~min}$ and $45 \mathrm{~s}$. The positive fragment was taken from the comedy film "When Harry Met Sally", showing a woman faking an orgasm in a full restaurant, in front of her male friend. The negative fragment was part of "The Champ", a film drama in which a young boy watches his father die after a boxing match. The neutral excerpt was taken from a BBC documentary on tidal waves in Australia. All three films were pilot tested among female students $(\mathrm{N}=11)$ and were shown to induce the desired emotional effect: when watching

Table 1

Overview of neutral words, positive emotional words, negative emotional words and food pictures used in the ST-IATs.

\begin{tabular}{llll}
\hline Neutral words & Positive emotional & Negative emotional & Food (pictures) \\
\hline Average & Happy & Sad & Potato crisps \\
Undecided & Joyful & Angry & Magnum ice cream \\
General & Satisfied & Gloomy & Chocolate \\
Normal & Cheerful & Lonely & Chocolate ice cream \\
Usual & Merry & Scared & French fries \\
Common & Relieved & Disappointed & Cupcake \\
\hline
\end{tabular}


the positive film, paired-sample t-tests showed an increase in positive mood (pre, $M=57.05, S D=17.08$; post, $M=66.77, S D=21.44$, $t(10)=3.76, p=.004)$ and a trend-significant decrease in negative mood (pre, $M=14.68, S D=13.65$; post, $M=8.36, S D=9.46$, $t(10)=2.04, p=.07)$. With regard to the neutral film, no change in positive (pre, $M=62.45, S D=15.21$; post, $M=58.50, S D=19.73$, $t(10)=0.99, p=.34$ ) or negative (pre, $M=12.18, S D=13.02$; post, $\mathrm{M}=13.32, \mathrm{SD}=13.66, t(10)=0.41, p=.69$ ) emotions was observed. The negative film clearly elicited a negative mood, with an increase in negative emotions (pre, $\mathrm{M}=14.64, \mathrm{SD}=10.24$; post, $\mathrm{M}=$ 29.36, $\mathrm{SD}=19.19, t(10)=3.48, p=.006)$ and a decrease in positive emotions (pre, $M=60.50, S D=18.16$; post, $M=46.05, S D=$ $23.14, t(10)=4.41, p=.001)$. In addition, both the positive and negative film clips were proven to be effective mood inducers in a previous study (Macht and Mueller, 2007). Several researchers have shown that film clips are effective in inducing positive and negative emotional states (Chua, Touyz, and Hill, 2004; Cools et al., 1992; Evers et al., 2009; Sheppard-Sawyer, McNally, and Fischer, 2000; Turner et al., 2010; Yeomans and Coughlan, 2009), and Gerrards-Hesse, Spies, and Hesse (1994) recommend to use either a film or story when the aim is to induce both happy and sad feelings in one study.

\subsubsection{Milkshakes}

Three vanilla milkshakes were freshly made for each participant right before she started the experiment. Milkshakes consisted of $125 \mathrm{~g}$ vanilla ice cream, $100 \mathrm{ml}$ full milk, $8 \mathrm{~g}$ vanilla sugar, and $25 \mathrm{~g}$ whipped cream. They were served in $300 \mathrm{~cm}^{3}$ milkshake cups, covered with a lid, and a straw was provided. The milkshakes weighed an average of $249.94 \mathrm{~g}$ and the total amount of kilocalories in one milkshake was $449.75 \mathrm{kcal}$. Milkshake intake was assessed by weighing milkshakes before and after the taste test. Participants were unaware of these measurements.

\subsubsection{Film and taste questionnaire}

The questionnaire consisted of 11 questions regarding the milkshakes and the film fragment. The questions were set up to match the cover story of the relationship between empathy and taste perception, and also to give participants the chance to drink as much of the milkshake as they would like. Nine questions referred to the taste of the milkshakes (e.g., for each milkshake how much they liked it and whether they all had the exact same taste), and two questions referred to the film clip. Except for the questions regarding liking of the milkshakes, none were included in the analyses.

\subsubsection{Mood}

Mood was measured by means of four $100 \mathrm{~mm}$ VAS scales, with 'not at all' anchored on the left side of the scale and 'extremely' on the right side. The scales were labeled sad, gloomy, happy and cheerful.

\subsection{6. $D E B Q$}

The DEBQ (Van Strien et al., 1986) consists of three subscales with a total of 33 items; an Emotional Eating subscale with 13 items, and External Eating and Restraint subscales with 10 items each. All items are scored on a 5-point Likert Scale, ranging from 'Never' to 'Very often'.

\subsubsection{Restraint Scale}

The Restraint Scale (Herman and Polivy, 1980) consists of 11 items, measuring attitudes towards eating, weight change and dieting. All items (except for items 10 and 11, asking about highest and ideal weight) are scored on 4 or 5 point Likert Scales, ranging from 'Never' or 'Not at all' to 'Always' or 'Very much'. The Restraint Scale was included to control for dietary restraint in participants, as research has shown that restrained and unrestrained eaters often differ in their food intake in the lab (e.g. Chua et al., 2004; Cools et al., 1992; Sheppard-Sawyer et al., 2000; Yeomans and Coughlan, 2009).

\subsubsection{Manipulation check and suspicion probe}

On the manipulation check form, participants filled out three VAS scales concerning how well they were able to concentrate on the film, how well they could taste the milkshake during the film, and how well they could taste the milkshakes after the film. Additional questions referred to their own description of what they thought the experiment was about, what they had lastly eaten and at what time, and whether they were currently dieting or restricting their food intake.

\subsection{Procedure}

Upon arrival in the laboratory, the participant was explained that the study was about empathy and taste perception. She signed an informed consent form and filled out a baseline VAS for mood. Subsequently, she was seated behind a computer to perform the positive emotion and negative emotion ST-IATs. After completion of the ST-IATs, the participant filled out another mood VAS. In the meantime, the experimenter collected the first milkshake from the fridge in a kitchen next door. The experimenter placed the milkshake in front of the participant, and gave the following instruction: 'You're about to see a film fragment and you should really focus and concentrate on the film, and empathize with it. While you do this, you should taste from this milkshake. However, you should not let the milkshake divert you from the film, it is important that you keep concentrating on the fragment. You will receive some questions later.' After this, the experimenter asked the participant to put on headphones, and started the film. The experimenter left the room, and returned when the film was finished. The participant received another mood VAS to fill out, and the experimenter replaced the first milkshake with two new ones, labeled A and B. The participant was informed she now had $5 \mathrm{~min}$ to complete a questionnaire with questions about the milkshake she drank during the film, the two new milkshakes, and the film. She was told that she could drink as much as she liked from the milkshakes. This was also repeated at the end of the questionnaire, where it said: 'You are now finished with the questionnaire. Wait until the experimenter returns. Feel free to drink some more of the milkshakes; left-overs will be thrown away.' The experimenter left the room and returned after $5 \mathrm{~min}$. The participant filled out a fourth mood VAS, followed by a manipulation check, the DEBQ and RS. Finally, height and weight were measured, and the participant received her reward for participation. The whole procedure lasted approximately $40 \mathrm{~min}$.

\subsection{Statistical analyses}

One-way ANOVAs were conducted to discover any pre-existing differences between the three groups, and paired sample t-test to check whether the mood manipulation was successful. Both scores on the positive scales were taken together and divided by two to calculate one general indicator of positive mood. The same was done with the negative mood scales. To investigate the usefulness of the ST-IAT over questionnaires when measuring emotional eating, a moderated regression analysis was carried out. Variables included in the regression were centered prior to entering them in the model. As indicated by Variance Inflation Factors (always close to 1) and tolerance (never below 0.2), there was no multicollinearity between the variables in any of the conducted regressions. In addition, the DurbinWatson statistic had a value close to 2 in all analysis, revealing that the assumption of independence of errors was met.

\section{Results}

\subsection{Participant exclusion}

Six participants were excluded because of missing data, misunderstood instructions (i.e., assuming that consumption of the whole 
milkshake was required during the film), or outlying (i.e., $z$-score $>$ 3.29) data on age, BMI, or milkshake consumption. Four additional participants were eliminated because they were aware of the true purpose of the study. In total, 112 out of 122 participants were included in the analyses.

\subsection{ST-IAT scores}

ST-IAT effects were computed with the D600 scoring algorithm, as suggested by Greenwald, Nosek, and Banaji (2003). Higher scores on the ST-IAT D600 indicate a faster response to emotion-food pairs than neutral-food pairs, and thus reflect a stronger association between emotions and food. In addition to the positive and negative ST-IATs separately, a combined average ST-IAT score was calculated by adding the scores on the negative ST-IAT to the positive version, and dividing it by two.

\subsection{Mood manipulation}

The mood manipulation was, despite careful pilot testing of the film clips, only partly successful. A 2 (time: before vs. after mood induction) $\times 3$ (condition: positive vs. neutral vs. negative) MANOVA on subjective mood ratings before and after viewing the film fragments was conducted, with the first factor within subjects and the second factor between subjects. The analysis revealed a significant multivariate interaction effect for time $\times$ positive $\operatorname{mood} F(2,108)=$ 75.23, $p<.001$ as well as for time $\times$ negative mood, $F(2,108)=$ $48.05, p<.001$. Subsequent simple main effects showed no significant differences in mood between conditions at baseline for the positive, $F(2,108)=.08, \mathrm{p}=.93$ nor negative, $F(2,08)=2.02, p=.14$ emotions. Participants in the negative condition increased in negative emotions (pre, $M=12.78, S D=10.75$; post, $M=29.85$, $S D=$ 18.73, $F(1,108)=95.66, p<.001)$, while positive emotions decreased (pre, $M=67.78, \quad S D=13.39$; post, $M=51.94, \quad S D=$ $16.70)$ from pre to post test, $F(1,108)=91.90, p<.001$. In the positive condition, the opposite effect was found, with an increase in positive emotions (pre, $\mathrm{M}=68.55, \mathrm{SD}=15.61$; post, $\mathrm{M}=79.30, \mathrm{SD}=$ $13.62, F(1,108)=43.49, p<.001)$ and a decrease in negative emotions (pre, $\mathrm{M}=14.58, \mathrm{SD}=11.89$; post, $\mathrm{M}=10.59, \mathrm{SD}=10.83$ ) from pre to post test, $F(1,108)=5.36, p=.02$. So both the negative and positive mood inductions were successful. However, the neutral film had the same effect as the positive film, increasing positive (pre, $\quad \mathrm{M}=67.29, \quad \mathrm{SD}=13.50 ; \quad$ post, $\quad \mathrm{M}=73.62, \quad \mathrm{SD}=14.61$, $F(1,108)=15.50, p=<.001)$ and decreasing negative emotions (pre, $\quad M=18.24, \quad S D=12.96 ; \quad$ post, $\quad M=14.74, \quad S D=13.72$, $F(1,108)=4.25, p=.04)$. Therefore, the participants in the positive and neutral conditions were combined and treated as one positive mood induction, and in further analyses compared to the negative condition.

\subsection{Participant characteristics}

A one-way ANOVA was used to compare the participants in both conditions on several baseline characteristics (i.e., age, BMI, mood at the start of the experiment and mood before watching the film, DEBQ emotional eating scores, DEBQ external eating scores, restraint, positive and negative ST-IAT emotional eating scores, and hours since last food intake). As Levene's test showed that homogeneity of variances was violated for $\operatorname{BMI}(F(1,110)=6.30, p=.01)$ and hours since last food intake $(F(1,110)=6.02, p=.02)$, Welch $F$ was used for these variables. As can be seen from Table 2, there were some marginally significant differences for hours since last food intake, as more time had passed for the positive condition compared to the negative condition. In addition, participants in the positive condition had slightly higher scores on the negative emotions at baseline,
Table 2

Means and standard deviations of participant characteristics per condition.

\begin{tabular}{|c|c|c|c|c|c|c|}
\hline & \multicolumn{2}{|c|}{$\begin{array}{l}\text { Positive } \\
\text { condition } \\
(\mathrm{N}=76)\end{array}$} & \multicolumn{2}{|c|}{$\begin{array}{l}\text { Negative } \\
\text { condition } \\
(\mathrm{N}=36)\end{array}$} & \multirow[t]{2}{*}{$\mathrm{F}$} & \multirow[t]{2}{*}{$p$} \\
\hline & M & SD & M & SD & & \\
\hline Age & 20.34 & 2.24 & 19.83 & 1.83 & 1.41 & .24 \\
\hline BMI & 22.56 & 2.30 & 22.23 & 3.09 & 0.33 & .57 \\
\hline Positive mood $1^{\mathrm{a}}$ & 67.72 & 13.35 & 70.17 & 13.75 & 0.80 & .37 \\
\hline Negative mood $1^{\mathrm{a}}$ & 15.55 & 11.62 & 11.69 & 9.58 & 3.00 & .09 \\
\hline Positive mood $2^{\mathrm{b}}$ & 67.49 & 13.35 & 70.17 & 13.75 & 0.01 & .92 \\
\hline Negative mood $2^{\mathrm{b}}$ & 16.70 & 12.63 & 12.78 & 10.75 & 2.59 & .11 \\
\hline Emotional eating ${ }^{\mathrm{c}}$ & 2.65 & 0.70 & 2.56 & 0.67 & 0.44 & .51 \\
\hline External eating ${ }^{\mathrm{c}}$ & 3.32 & 0.53 & 3.26 & 0.51 & 0.34 & .56 \\
\hline Dietary restraint ${ }^{\mathrm{d}}$ & 12.53 & 5.05 & 11.17 & 5.70 & 1.63 & .21 \\
\hline Positive ST-IAT score ${ }^{\mathrm{e}}$ & 0.21 & 0.31 & 0.32 & 0.34 & 3.05 & .08 \\
\hline Negative ST-IAT score $\mathrm{e}^{\mathrm{e}}$ & 0.21 & 0.34 & 0.21 & 0.27 & 0.01 & .93 \\
\hline Hours since last meal & 3.41 & 1.84 & 2.84 & 1.17 & 3.91 & .05 \\
\hline
\end{tabular}

a Mood measured at baseline by $100 \mathrm{~mm}$ VAS scales, higher scores indicate better mood.

b Mood measured after ST-IATs but before film by 100 mm VAS scales, higher scores indicate better mood

c Emotional Eating and External Eating measured by DEBQ

d Restraint measured by Restraint Scale.

e ST-IAT scores computed with the D600 scoring algorithm, higher scores indicate higher degree of emotional eating.

whereas people in the negative condition scored marginally higher on the positive ST-IAT.

\subsection{Correlations}

Pearson correlations were calculated for the negative ST-IAT, positive ST-IAT, and DEBQ emotional eating scale. Both ST-IATs correlated significantly with each other, $r=.34, p<.001$, but no correlation was found between the DEBQ emotional eating scale and the negative ST-IAT, $r=-.01, p=.92$, nor the DEBQ emotional eating scale and the positive ST-IAT, $r=.00, p=.99$.

\subsection{Moderated regression}

The amount of milkshakes consumed (in grams) per condition is shown in Table 3. Milkshake intakes during the film, $F(1,110)=$ $7.65, p=.007$, after the film, $F(1,110)=6.57, p=.01$, and in total, Welch's $F(1,101.54)=14.68, p<.001$ were higher in the positive compared to the negative condition.

The first regression analysis focused on milkshake consumption after watching the film clips. Scores on dietary restraint (RS), external eating (DEBQ), hours since last meal, ratings of milkshake palatability and grams of milkshake consumed during the film were entered as covariates in the first block. Only palatability ratings and previous milkshake consumption were significant and used in the subsequent analysis. In the second block, either the positive ST-IAT, negative ST-IAT, combined ST-IAT, or DEBQ emotional eating score was added, together with condition. The interaction between ST-IAT or DEBQ and condition was entered in the third and final block. Results showed no

Table 3

Means and standard deviations of grams of milkshake intake during the film, after the film, and in total per condition.

\begin{tabular}{|c|c|c|c|c|}
\hline & \multicolumn{2}{|c|}{$\begin{array}{l}\text { Positive } \\
\text { condition } \\
(\mathrm{N}=76)\end{array}$} & \multicolumn{2}{|c|}{$\begin{array}{l}\text { Negative } \\
\text { condition } \\
(\mathrm{N}=36)\end{array}$} \\
\hline & M & SD & M & SD \\
\hline Milkshake consumption during film & 71.46 & 47.03 & 46.49 & 39.01 \\
\hline Milkshake consumption after film & 113.25 & 67.25 & 81.24 & 47.77 \\
\hline Total milkshake consumption & 184.71 & 97.66 & 126.70 & 61.12 \\
\hline
\end{tabular}


Table 4

Results of Hierarchical Regression Analysis on milkshake consumption during film.

\begin{tabular}{|c|c|c|c|c|c|c|c|c|c|c|c|c|}
\hline \multirow{3}{*}{$\begin{array}{l}\text { Steps and } \\
\text { variables }^{\mathrm{a}}\end{array}$} & \multicolumn{6}{|c|}{ Positive ST-IAT } & \multicolumn{6}{|c|}{ Negative ST-IAT } \\
\hline & \multicolumn{2}{|l|}{ Step 1} & \multicolumn{2}{|l|}{ Step 2} & \multicolumn{2}{|l|}{ Step 3} & \multicolumn{2}{|l|}{ Step 1} & \multicolumn{2}{|l|}{ Step 2} & \multicolumn{2}{|l|}{ Step 3} \\
\hline & B & SE & B & SE & B & SE & B & SE & B & SE & B & SE \\
\hline Palatability & $15.27^{* * *}$ & 4.08 & $13.40^{\text {*** }}$ & 4.58 & $13.29^{* * *}$ & 4.52 & $15.27^{\text {*** }}$ & 4.08 & $12.68^{\text {*** }}$ & 4.62 & $12.54^{\text {*** }}$ & 4.58 \\
\hline EE measure ${ }^{\mathrm{b}}$ & & & $22.24^{*}$ & 13.18 & $40.75^{* *}$ & 16.43 & & & 5.49 & 13.22 & 18.49 & 14.97 \\
\hline Condition & & & -13.32 & 9.91 & -11.64 & 9.84 & & & -11.68 & 9.98 & -11.81 & 9.88 \\
\hline EEx condition & & & & & $-49.75^{*}$ & 26.88 & & & & & $-55.12^{*}$ & 30.80 \\
\hline $\mathrm{R}^{2}$ & \multirow{2}{*}{\multicolumn{2}{|c|}{$\begin{array}{c}.114 \\
.114^{* * *}\end{array}$}} & \multirow{2}{*}{\multicolumn{2}{|c|}{$\begin{array}{l}.148 \\
.034\end{array}$}} & \multirow{2}{*}{\multicolumn{2}{|c|}{$\begin{array}{l}.174 \\
.027^{*}\end{array}$}} & \multirow{2}{*}{\multicolumn{2}{|c|}{$\begin{array}{c}.114 \\
.114^{* * * *}\end{array}$}} & \multirow{2}{*}{\multicolumn{2}{|c|}{$\begin{array}{l}.127 \\
.012\end{array}$}} & \multirow{2}{*}{\multicolumn{2}{|c|}{$\begin{array}{l}.152 \\
.026^{*}\end{array}$}} \\
\hline$\Delta \mathrm{R}^{2}$ & & & & & & & & & & & & \\
\hline
\end{tabular}

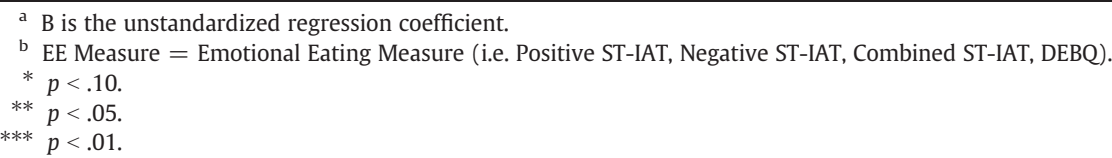

effects of ST-IAT, DEBQ, or condition on food intake, nor were there any interaction effects (positive ST-IAT, all $t s<1.27$, all $p s>.21$; negative ST-IAT, all $t \mathrm{~s}<1.42$, all $p s>.16$; combined ST-IAT, all $t s<1.33$, all ps > .19; DEBQ all ts $<1.13$, all $p s>.21$ ).

In the second regression analysis, milkshake consumption during the film clip was entered as the dependent variable. Because one participant did not drink anything from the milkshake during the film, 111 participants were included in this analysis. No other changes were made, except that there was only one covariate, namely palatability of the milkshake consumed during the film. Different patterns emerged for the two types of ST-IAT, the combined ST-IAT, and the DEBQ, which are described in more detail in the following paragraphs. The results of the regression are shown in Table 4. Simple slopes and interactions with standardized regression coefficients for participants scoring high $(+1 \mathrm{SD})$ and low $(-1 \mathrm{SD})$ on all measures of emotional eating separately are plotted in Fig. 1.

\subsubsection{Positive ST-IAT as a measure of emotional eating}

Analyzing the positive ST-IAT as predictor of milkshake consumption during the film clip showed a trend-significant interaction between the positive ST-IAT and condition, $\beta=-.21, t(110)=1.85$, $p=.07$. More specifically, there was a significant difference between high and low positive ST-IAT scorers in the positive mood condition, with high scorers consuming significantly more milkshake than low scorers, $\beta=.28, t(110)=2.48, p=.02$, while there were no differences between high and low positive ST-IAT scorers in the negative mood condition, $\beta=-.06, t(110)=0.42, p=.67$. Looking at differences in food intake between the positive and negative conditions for low and high emotional eaters separately, there was no difference for low scorers, $\beta=.04, t(110)=0.31, p=.76$, but there was for high scorers. They consumed significantly more food in the positive compared to the negative mood condition, $\beta=-.28, t(110)=$ 2.21, $p=.03$. In sum, these findings confirm the hypothesis that IAT-positive emotional eaters consume more food than IAT-positive non-emotional eaters, and that this effect is specific to the positive mood condition.

\subsubsection{Negative ST-IAT as a measure of emotional eating}

With regard to the negative ST-IAT, high and low scorers did not differ on food intake in either the positive, $\beta=.13, t(110)=1.24$, $p=.22$ or negative, $\beta=-.25, t(110)=1.36, p=.18$ mood condition. However, there was a trend-significant interaction between the negative ST-IAT and mood condition, $\beta=-.18, t(110)=1.79, p=$ .08. The high ST-IAT emotional eaters consumed significantly more food in the positive than in the negative condition, $\beta=-.30$, $t(110)=2.10, p=.04$, while this was not found for those scoring low on negative ST-IAT emotional eating, $\beta=.06, t(110)=0.39$, $p=.70$. So, although IAT-negative emotional eaters did overeat after an emotion induction, they unexpectedly consumed more after positive than after negative emotions.

\subsubsection{Combined ST-IAT as a measure of emotional eating}

When the positive and negative ST-IATs were combined into one single ST-IAT score, reflecting typical emotional eaters, a pattern similar to the one observed in the positive ST-IAT emerged, with a significant interaction between condition and ST-IAT, $\beta=-.21, t(110)=$ $2.06, p=.04$. While there were no differences between high and low emotional eaters in the negative condition, $\beta=-.20, t(110)=1.12$, $p=.27$, there was again higher food intake in the positive condition for those with higher ST-IAT scores, $\beta=.22, t(110)=2.16, p=.03$ than those with lower scores. In addition, high scorers consumed significantly more milkshake when in a positive compared to a negative mood, $\beta=-.31, t(110)=2.32, p=.02$, whereas this did not occur within the group with low ST-IAT scores, $\beta=.08, t(110)=0.57$, $p=.57$. Thus, combined ST-IAT-emotional eaters consumed more milkshake than combined ST-IAT-non-emotional eaters, but only when in a positive mood.

\subsubsection{DEBQ as a measure of emotional eating}

The DEBQ revealed no significant effects. There was no interaction, $\beta=.03, t(110)=0.25, p=.80$, nor were there any differences between the high and low emotional eaters in either mood condition (positive: $\beta=-.02, t(110)=0.16, p=.87$; negative: $\beta=-.04$, $t(110)=0.25, p=.84)$. In addition, neither the low, $\beta=-.14$, $t(110)=1.03, p=.31$ nor high emotional eaters $\beta=-.10$, $t(110)=0.68, p=.50$ differed in food intake between conditions. Taken together, DEBQ-emotional eating scores did not predict food intake.

\subsection{Spin-off: milkshake palatability}

Although not directly related to the hypotheses, but of relevance for the study, was an interesting finding with regard to milkshake palatability that emerged during analyses. Independent samples t-tests showed that participants in both mood conditions rated the two milkshakes tasted after the film equally palatable (first milkshake: positive condition, $\mathrm{M}=3.38, \mathrm{SD}=.96$, negative condition, $\mathrm{M}=$ 3.10, $\mathrm{SD}=.94, t(115)=1.51, p=.13$; second milkshake: $\mathrm{M}=$ $3.46, \mathrm{SD}=.96$, negative condition, $\mathrm{M}=3.18, \mathrm{SD}=.91, t(115)=$ $1.52, p=.13)$. However, the same milkshake consumed while 


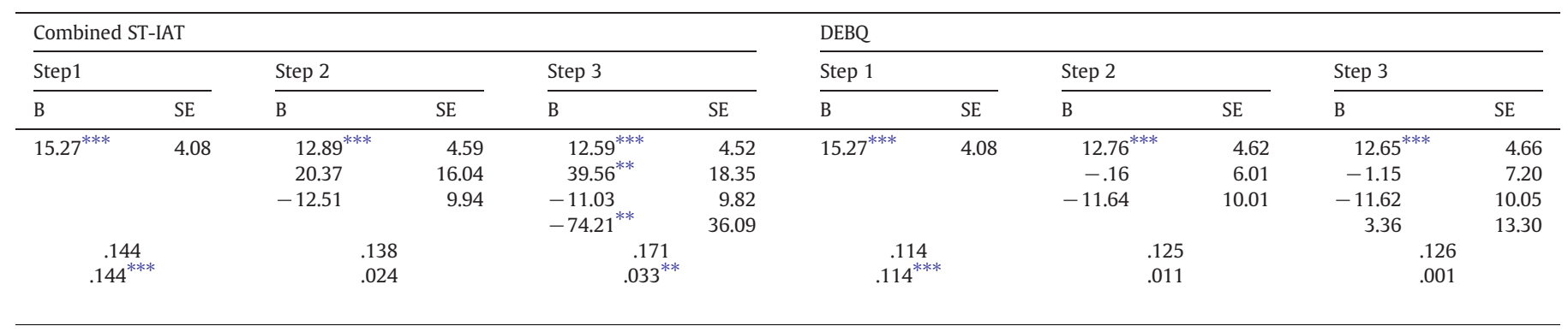

watching the film was rated significantly tastier by the participants who had watched the positive film, $\mathrm{M}=3.82$, $\mathrm{SD}=.85$ compared to those who had watched the negative film, $\mathrm{M}=2.74, \mathrm{SD}=.99$, $t(114)=6.06, p=.00$. In addition, paired samples t-tests revealed that while participants in the positive condition rated the milkshake consumed during the movie $(\mathrm{M}=3.82, \mathrm{SD}=.85)$ as more palatable than the milkshakes after the movie (first milkshake: $M=3.38$, $\mathrm{SD}=.96, t(76)=4.33, p=.00 ;$ second milkshake: $\mathrm{M}=3.45$, $\mathrm{SD}=.97, t(76)=3.79, p=.00)$, this effect was opposite for the negative condition, where the after-movie milkshakes were judged to be tastier (first milkshake: $\mathrm{M}=3.10, \mathrm{SD}=.94, t(38)=2.02$, $p=.05$; second milkshake: $\mathrm{M}=3.18, \mathrm{SD}=.91, t(38)=2.49$, $p=.02$ ) compared to the milkshake ingested during the movie $(\mathrm{M}=2.74, \mathrm{SD}=.99)$. In sum, these results show that emotional stimuli presented during milkshake consumption may influence its palatability.

\section{Discussion}

The present study was designed to investigate the ST-IAT as a predictor of emotional eating, and to compare it to the prevailing method of emotional eating measures, namely questionnaires. In general, for both separate positive and negative ST-IATs and the combined score, differences emerged in milkshake consumption in emotional and non-emotional eaters while watching a movie, depending on the induced mood. More specifically, with regard to the positive ST-IAT, results showed that IAT-positive emotional eaters in the positive condition consumed significantly more milkshake than people without these associations, and they also drank more in the positive than in the negative condition. The negative ST-IAT revealed a significant difference for IAT-negative emotional eaters, who, contrary to our hypothesis, consumed more milkshake while watching a positive film compared to a negative film. When the two ST-IATs were combined into one, IAT-emotional eaters displayed higher milkshake consumption than IAT-non-emotional eaters in the positive condition, and the same difference between conditions emerged for the high scoring group: IAT-emotional eaters drinking more milkshake in a positive mood. Finally, looking at the DEBQ there were no differences between the two types of eaters. Both DEBQ-emotional and DEBQ-non-emotional eaters consumed the same amount of food in each condition, and there were no differences between mood conditions within the groups.

In short, IAT-emotional eaters in the present study consume more food when in a positive mood compared to a negative mood. Moreover, in the case of the positive and combined ST-IAT, they consume more than IAT-non-emotional eaters when in a positive mood, and with all three ST-IAT measures food intake remains constant over groups when in a negative mood. There were no intake differences at all between DEBQ-emotional and DEBQ-non-emotional eaters. These findings only apply to food consumption during the experience of emotions; milkshake consumption after mood induction was not influenced by any of the emotional eating scores.

The findings on the DEBQ are not completely unexpected. Bongers, Jansen, Havermans, Roefs, and Nederkoorn (2013) also did not find DEBQ-emotional eaters to consume more food when in a negative mood as compared to DEBQ-non-emotional eaters, although they did find an increase in food consumption in the emotional eaters when they were in a positive state as compared to a neutral state. However, some other recent studies (Evers et al., 2009; Kenardy, Butler, Carter, and Moor, 2003) found no effect of DEBQ-scores on food intake in emotional eaters, neither after a negative nor after a positive mood manipulation. Interesting to note is that while emotional eating has always been thought to happen in response to negative emotions (Schachter, Goldman, and Gordon, 1968; Van Strien et al., 1986), these recent study results are consistent in showing that emotional eaters actually do not overeat in response to specifically negative emotions, neither when emotional eating is measured by self-report or by using an ST-IAT.

Increased food intake after positive or negative emotions is not something new; several researchers found this in for example the obese (Chua et al., 2004), restrained eaters (Cools et al., 1992; Sheppard-Sawyer et al., 2000; Yeomans and Coughlan, 2009), and overweight people high in negative affect (Jansen et al., 2008). However, in emotional eaters it does not seem to be that straightforward. Why do emotional eaters not overeat after negative emotions? A first explanation is that they would overeat in a negative affective state in natural situations, but not in the laboratory. Participants might feel uncomfortable, self-aware and observed in a laboratory environment, which influences their food intake. However, because studies do show overeating after positive emotions, as well as overeating in other types of eaters, this does not seem a likely explanation. In addition, real-life diary studies conducted by Adriaanse et al. (2011) and Conner et al. (1999) also did not find effects of emotional eating scores on food consumption. A second possibility is that current measures of emotional eating are not valid, as was suggested by Adriaanse et al. (2011). Thirdly, it could be argued that negative emotional eating is only observable in a clinical population. Therefore, it would be interesting to repeat the current study in a clinical sample identified to suffer from emotional eating, such as binge eaters (Eldredge and Agras, 1996; Pinaquy, Chabrol, Simon, Louvet, and Barbe, 2003). Kenardy et al. (2003) suggested that only clinical samples increase food intake after negative emotions, or, alternatively, that a very strong mood manipulation is necessary to evoke these responses in non-clinical samples. In contrast to this, Macht and Simons (2000) found in their field study that students had a stronger motivation to eat after negative than after positive emotions. Fourth, overeating might only happen with certain negative emotions, and this might differ between people: Whereas some people overeat when feeling sad, others may only increase their food intake when angry or stressed. Current 
questionnaires, as well as the ST-IAT, do not differentiate between specific emotions. Perhaps there would be more convincing results with regard to negative emotions when they are tailored to the individual.

Another issue that warrants further explanation is that overeating only occurred during the emotional experience, but not after. Although these findings are in line with Evers et al. (2009) and Kenardy et al. (2003), who both found no differences between DEBQ-emotional and non-emotional eaters on food intake after a mood manipulation, they are in contrast with our (Bongers et al., 2013) previous study, at least with regard to the positive emotions, during which DEBQ-emotional eaters overate. To our knowledge, the current study is the first that measured food consumption while undergoing an emotional experience, and it raises the question why overeating does occur at this point in time, but not afterwards. One possibility is that this is due to the food consumption during the film: there might have been differences in milkshake intake after the film if the participants had not already consumed some milkshake. A second possibility is that the effects of manipulations used in the laboratory fade away quickly, thereby being capable of eliciting increased food intake during the emotional experience, but not thereafter. Stronger manipulations, possibly tailored to the individual, might be more successful to induce longer-lasting effects. However, what these stronger manipulations should entail remains unclear; the aforementioned studies on emotional eating have used several methods of mood induction, such as film clips, bogus feedback on performance, vignettes describing emotional evens, and recalling sad memories, of which none appeared to be sufficient.

Deviating from the hypotheses of the study, but relevant to the obtained findings, is the surprising influence of emotional valence of movie fragments on taste perception. Participants in the negative condition rated the milkshake consumed during the movie as significantly less tasty than the milkshakes they received after the movie, even though all milkshakes were identical. It is interesting to see that judgments of taste depend on mood. This might mean that low mood makes food less tasty while being happy makes food taste better. Because palatability was added into the analyses as a covariate, this should not have influenced the results. The other way around, the film shown in the control condition elicited a positive mood in participants, which may have been caused by the simultaneous intake of a sweet, tasty, and high-caloric milkshake during this neutral manipulation. The control film clip was pilot tested before the study started, but without simultaneous milkshake intake, and was found not to interfere with the participant's mood. Although the influence of food on the appraisal of a neutral stimulus has never been tested directly, there is some indirect evidence that sweet and high-caloric foods can increase mood (Kenardy et al., 2003; Macht and Dettmer, 2006; Macht and Mueller, 2007). This might be a good example of evaluative conditioning during which a neutral stimulus changes in valence after being systematically paired with a liked or disliked stimulus: evaluative conditioning might explain why drinking a tasty milkshake during a neutral movie improves mood.

These results could also contribute to an explanation for the aforementioned issue of an absence of any effects in the negative mood condition. As the milkshakes appeared to have a positive effect on mood change after the neutral film, they might have been able to influence mood after the negative movie clip in a similar manner. The positive feelings evoked by milkshake consumption may have attenuated the negative feelings experienced during the negative manipulation. Therefore, although participants did decrease significantly in mood, this decrease may not have been enough to actually instigate overeating. When we apply this line of reasoning to the positive condition, it could be argued that the milkshake consumption intensified the positive emotions raised by the positive movie, therefore making it possible to find effects on food intake in this condition. Taking it one step further, these findings could explain why we did not find any effects on food intake after the film, or why some previous studies (e.g. Evers et al., 2009) failed to find a relationship between mood change and food consumption in emotional eaters: the manipulation was only strong enough when there was a combination of film and palatable food, and effects diminished when the emotion inducers are taken away.

Although the obtained findings are novel and cannot be generalized to other populations or contexts outside of the laboratory, the present results suggest that this ST-IAT has potential as a measure of emotional eating. Especially the positive ST-IAT showed predictive validity in
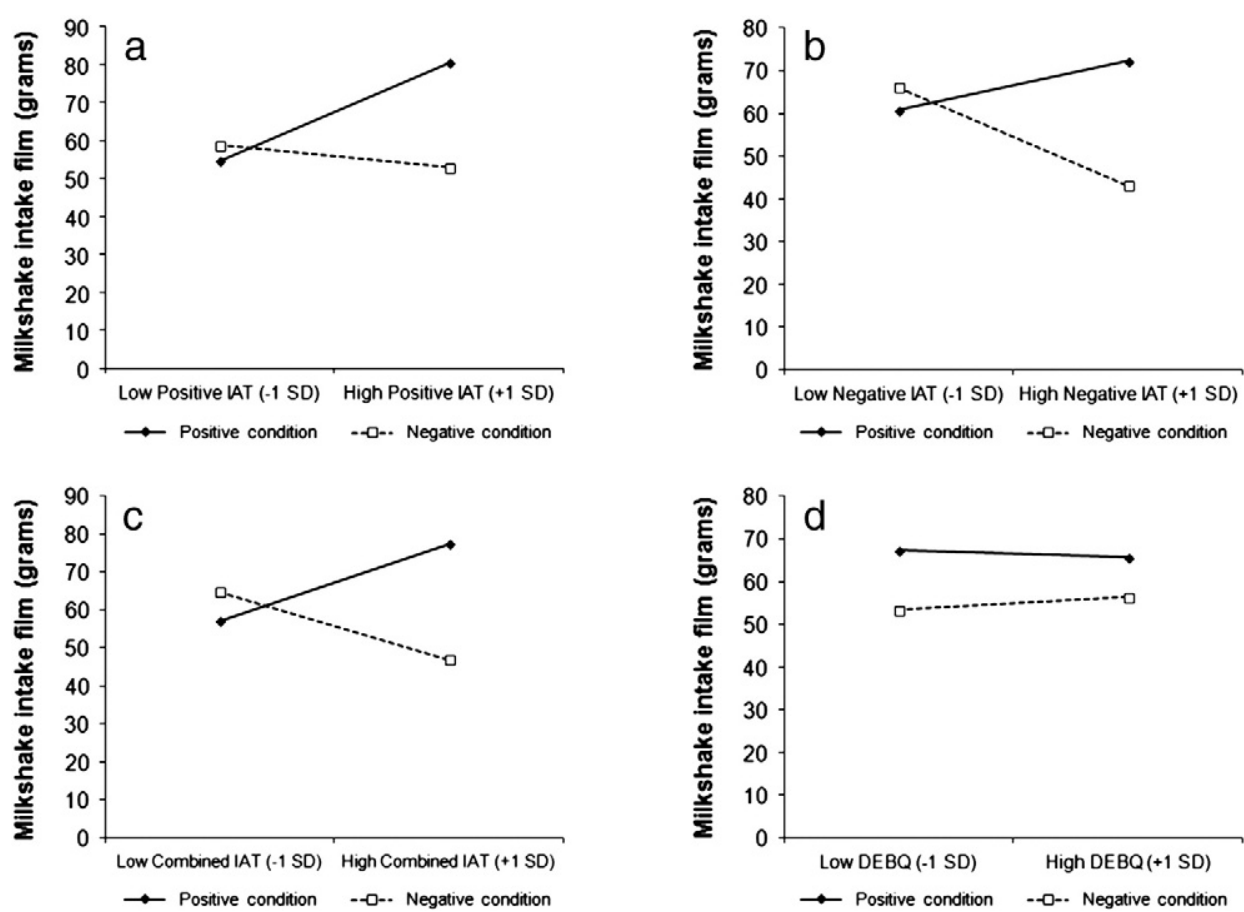

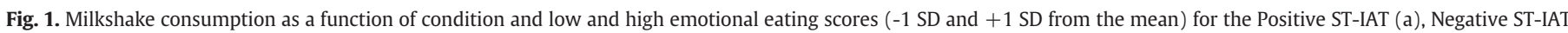
(b), Combined ST-IAT (c), and DEBQ score (d). 
distinguishing those who will or will not overeat after positive emotions. The negative ST-IAT was also able to differentiate between emotional and non-emotional eaters, although it unexpectedly predicted overeating after positive, and not negative, emotions. Future studies on its validity and usability in eating behavior studies are needed.

\section{Role of funding sources}

Funding for this study was provided by the Netherlands Organisation for Scientific Research (NWO): Vici Grant 453.10.006, awarded to Anita Jansen. NWO had no role in the study design, collection, analysis or interpretation of the data, writing the manuscript, or the decision to submit the paper for publication.

\section{Contributors}

Peggy Bongers and Anita Jansen designed the study and wrote the protocol. Anne Roefs designed the Implicit Association Test that was used in the study. Peggy Bongers, Anne Roefs and Katrijn Houben conducted the statistical analyses. Peggy Bongers wrote the first draft of the manuscript. All authors contributed to and have approved the final manuscript.

\section{Conflict of interest}

All authors declare that they have no conflict of interest.

\section{References}

Adriaanse, M. A., de Ridder, D. T. D., \& Evers, C. (2011). Emotional eating: Eating when emotional or emotional about eating? Psychology \& Health, 26(1), 23-39.

Arnow, B., Kenardy, J., \& Agras, W. S. (1995). The Emotional Eating Scale: The development of a measure to assess coping with negative affect by eating. Internationa Journal of Eating Disorders, 18(1), 79-90.

Bongers, P., Jansen, A., Havermans, R., Roefs, A., \& Nederkoorn, C. (2013). Happy eating: The underestimated role of overeating in a positive mood. Appetite, 67, 74-80.

Bruch, H. (1964). Psychological aspects of overeating and obesity. Psychosomatics, 5(5), 269.

Chua, J. L., Touyz, S., \& Hill, A. J. (2004). Negative mood-induced overeating in obese binge eaters: An experimental study. International Journal of Obesity, 28(4), 606-610.

Conner, M., Fitter, M., \& Fletcher, W. (1999). Stress and snacking: A diary study of daily hassles and between-meal snacking. Psychology \& Health, 14(1), 51-63.

Cools, J., Schotte, D. E., \& McNally, R. J. (1992). Emotional arousal and overeating in restrained eaters. Journal of Abnormal Psychology, 101(2), 348-351.

De Houwer, J., Teige-Mocigemba, S., Spruyt, A., \& Moors, A. (2009). Implicit measures: A normative analysis and review. Psychological Bulletin, 135(3), 347.

Eldredge, K. L., \& Agras, W. S. (1996). Weight and shape overconcern and emotional eating in binge eating disorder. International Journal of Eating Disorders, 19, 73-82.

Evers, C., de Ridder, D. T. D., \& Adriaanse, M. A. (2009). Assessing yourself as an emotional eater: Mission impossible? Health Psychology, 28(6), 717-725.

Ganley, R. M. (1989). Emotion and eating in obesity: A review of the literature. International Journal of Eating Disorders, 8(3), 343-361.
Gerrards-Hesse, A., Spies, K., \& Hesse, F. W. (1994). Experimental inductions of emotional states and their effectiveness: A review. British Journal of Psychology, 85(1), $55-78$

Greenwald, A. G., McGhee, D. E., \& Schwartz, J. L. K. (1998). Measuring individual differences in implicit cognition: The implicit association test. Journal of Personality and Social Psychology, 74(6), 1464-1480.

Greenwald, A. G., Nosek, B. A., \& Banaji, M. R. (2003). Understanding and using the Implicit Association Test: I. An improved scoring algorithm. Journal of Personality and Social Psychology, 85(2), 197-216.

Herman, C. P., \& Polivy, J. (1980). Restrained eating. In A. J. Stunkard (Ed.), Obesity (pp. 208-225). Philadelphia: Saunders.

Jansen, A., Nederkoorn, C., Roefs, A., Bongers, P., Teugels, T., \& Havermans, R. (2011). The proof of the pudding is in the eating: Is the DEBQ-External Eating Scale a valid measure of external eating? International Journal of Eating Disorders, 44(2), $164-168$.

Jansen, A., Vanreyten, A., van Balveren, T., Roefs, A., Nederkoorn, C., \& Havermans, R. (2008). Negative affect and cue-induced overeating in non-eating disordered obesity. Appetite, 51(3), 556-562.

Karpinski, A., \& Steinman, R. B. (2006). The Single Category Implicit Association Test as a measure of implicit social cognition. Journal of Personality and Social Psychology, 91(1), 16-32.

Kenardy, J., Butler, A., Carter, C., \& Moor, S. (2003). Eating, mood, and gender in a noneating disorder population. Eating Behaviors, 4(2), 149-158.

Macht, M., \& Dettmer, D. (2006). Everyday mood and emotions after eating a chocolate bar or an apple. Appetite, 46(3), 332-336.

Macht, M., \& Mueller, J. (2007). Immediate effects of chocolate on experimentally induced mood states. Appetite, 49(3), 667-674.

Macht, M., \& Simons, G. (2000). Emotions and eating in everyday life. Appetite, 35(1), 65-71.

Masheb, R. M., \& Grilo, C. M. (2006). Emotional overeating and its associations with eating disorder psychopathology among overweight patients with binge eating disorder. International Journal of Eating Disorders, 39(2), 141-146.

Patel, K. A., \& Schlundt, D. G. (2001). Impact of moods and social context on eating behavior. Appetite, 36(2), 111-118.

Pinaquy, S., Chabrol, H., Simon, C., Louvet, J., \& Barbe, P. (2003). Emotional eating, alexithymia, and binge eating disorder in obese women. Obesity Research, 11, 195-201.

Schachter, S., Goldman, R., \& Gordon, A. (1968). Effects of fear, food deprivation, and obesity on eating. Journal of Personality and Social Psychology, 10(2), 91-97.

Sheppard-Sawyer, C. L., McNally, R. J., \& Fischer, J. H. (2000). Film-induced sadness as a trigger for disinhibited eating. International Journal of Eating Disorders, 28(2), 215-220.

Turner, S. A., Luszczynska, A., Warner, L., \& Schwarzer, R. (2010). Emotional and uncontrolled eating styles and chocolate chip cookie consumption. A controlled trial of the effects of positive mood enhancement. Appetite, 54(1), 143-149.

Van Strien, T., Frijters, J. E., Bergers, G. P., \& Defares, P. B. (1986). The Dutch Eating Behavior Questionnaire (DEBQ) for assessment of restrained, emotional, and external eating behavior. International Journal of Eating Disorders, 5(2), 295-315.

Yeomans, M. R., \& Coughlan, E. (2009). Mood-induced eating. Interactive effects of restraint and tendency to overeat. Appetite, 52(2), 290-298. 